\title{
Socio-psychological aspects of the introduction of information modeling technologies in construction
}

\author{
Tatiana Magera ${ }^{1, *}$ \\ ${ }^{1}$ Moscow State University of Civil Engineering, 129337, 26 Yaroslavskoye Shosse, Moscow, Russia
}

\begin{abstract}
The Fourth Industrial Revolution from the forecasted phenomena becomes a reality of today. The introduction of information modeling technologies in construction is in accordance with the spirit of the times and thсме opportunity to move from the lagging sectors to the advanced ones. Such a transition is accompanied by socio-psychological aspects, connected, first of all, with the features of interaction in human society. The technologies of the Fourth Industrial Revolution and the risks associated with them in comparison with modern building trends are considered, the difficulties in applying BIM technologies in the sociopsychological context are indicated, and preventive measures are proposed to prevent such difficulties through changing the ways of organizing joint activities of construction companies around a unified information model.
\end{abstract}

\section{Introduction}

The construction industry is transforming under the influence of modern realities, caused by the introduction of information technology. Today, it is increasingly said that the Fourth revolution is coming to replace the Third ("digital") industrial revolution. Klaus Schwab, founder and chairman of the World Economic Forum in Davos, characterizes the Fourth Industrial Revolution by merging technology and blurring the physical, digital and biological boundaries [1]. The concept of "Industry 4.0" was also formulated in 2011 by K. Schwab, and the term "Industry 4.0" was introduced by the Communication Promoters Group of the Industry-Science Research Alliance to describe the large-scale application of information and communication technologies in industrial production. "4.0" means the direct continuation of the three previous industrial revolutions, as a potential revolutionary influence of this trend. Since 2011, initiatives have emerged around the world relating to combining industrial production, digital technologies and the Internet (for example, the Industrial Internet Consortium in the United States and the Industrial Value Chain Initiative in Japan) [2]. Industry 4.0 is another name for the Fourth Industrial Revolution, which, contrary to delusions, is not limited to complete automation and digitalization.

BIM is a technology actively implemented in construction, it is considered in this paper as an example of the implementation of the technologies of the Fourth Industrial

\footnotetext{
* Corresponding author: mageratatiana@mail.ru
} 
Revolution. Despite the legitimacy of fears associated with the impending mass unemployment associated with the increasing automation and development of robotics, BIM does not replace a person, but it changes the content of professional activity and specifics of interaction in the course of work on the information model of a building. There are questions connected with the need to provide for possible difficulties and increase the efficiency of functioning of complicated modern high-tech complexes in construction taking into account the human factor. According to the Dictionary of EMERCOM of Russia, the human factor is defined as psychological and other characteristics of a person, his (her) capabilities and limitations determined in the specific conditions of his (her) activity [3]. Thus, all issues relevant to human characteristics that allow qualitatively to carry out professional activity in the conditions of introduction of information modeling technologies in construction are actual. And not at any cost. In this paper, the sociopsychological context is considered, with emphasis on the principles of optimality, balance, and human-centered.

\section{Tasks}

In the light of these issues, such tasks are solved:

First, to compare the technologies of the Fourth Industrial Revolution (according to K. Schwab) and the modern trends in construction, due to the introduction of information modeling technologies.

Secondly, to clarify the terminology used in the described processes: Fourth Industrial Revolution, Technologies of the Fourth Industrial Revolution, Industry 4.0, BIM and BIM technologies, virtual reality, augmented reality, mixed reality, intergroup adaptation.

Thirdly, to identify the possible risks and "bottlenecks" associated with the introduction of information modeling technologies in construction.

Fourth, to predict socio-psychological aspects accompanying the transition to Industry 4.0 in construction, including in the field of personnel management. The study of sociopsychological aspects is based on the approaches of Russian scientists V.S. Ageyev, A.V. Bulgakov, I.R. Sushkov to intergroup relations, interactions, MGA; on the social constructivist approach developed in the works of G.M. Andreeva, D. Best, K. Gergen; on the approaches of V.V. Loginova, Yegorova N.M. on the creation of the deterministic model of the MGA; on the views of A.L. Zhuravlev, V.P. Pozdnyakov for joint activities; on the concepts of T.Yu. Bazarov, V.N. Knyazev, Yu.V. Sinyagin, E.P. Utlika about sociopsychological methods of managing intergroup interactions in social systems.

Fifthly, to propose preventive measures of a social-psychological nature, including in the field of personnel management, to anticipate the negative consequences of the introduction of information modeling technologies in construction.

\section{Materials and methods}

K. Schwab described the twelve technologies driving the Fourth Industrial Revolution associated with the expansion of digital technologies (new computing technologies, blockchain and distributed registry technology, Internet of Things, IoT), the transformation of the physical world (artificial intelligence (AI) and robots, advanced materials, additive production and multivariate printing), human change (biotechnology, neurotechnology, virtual and augmented reality) and environmental integration (acquisition, accumulation and transmission of energy, geoengineering, space technology) [1]. All technologies are understood both from the point of view of breakthroughs, able to transform mankind into an era of prosperity through comfort and convenience, and from a negative point of view, 
allowing through fears and anxieties to foresee undesirable consequences [4]. An example of the implementation of today's (or, to be more exact, tomorrow's) technologies in the construction industry is the use of BIM-technologies (Building Information Modeling), it is a process that creates, develops and improves the information model of a building at each stage [5].

It should be emphasized that the changes occur very quickly. The pace of implementation of the described technologies is such that it makes sense to avoid disputes about whether the Fourth Industrial Revolution is a predictable event / process or an already observed reality. In addition, if in early 2018 it was believed that the introduction of information modeling technologies for construction in Russia will take 2-3 years, after the Order of the President of Russia to the Prime Minister (PR-1235 from 19.07.2018) about the introduction of information modeling technology in construction less than for one year [6], it became clear that the timing of such implementation is extremely tight.

BIM in one way or another, directly or indirectly, employs the twelve technologies described above:

- digital tools are the basis of information modeling;

- "digital memory", created due to the technology of block-chain, is relevant in the space of joining the boundaries between the material and digital worlds;

- IoT, whose value is not only in connecting to the Internet of intelligent devices and services on this basis, but also in that it allows you to operate data of potential consumers, which, including with a positive outcome, can prevent various destructive consequences;

- AI and robots have long been used in construction. Even with restrictions on the use of robots on a construction site (for example, unpredictability of the environment and a large number of people), the potential of robotics has grown significantly over the past 10 years [7];

- achievements in materials science for construction cannot be overestimated and difficult to list, take into account all the criteria for developing this direction: lightness, wear resistance, fire safety, environmental friendliness, intended for various weather and climate conditions, etc.;

- the trajectory of the growth of technology related to the use of 3D printers, shows that they are able to turn over the entire system of construction production, because processes of $3 \mathrm{D}$ printing, known for more than 25 years, today have become smaller, cheaper, more qualitative and more flexible;

- the use of biomaterials in construction can also be associated with new materials. For example, solving the issue of the durability of construction materials. Dutch scientists added capsules with a certain type of living bacteria and nutrients (calcium lactate) into the concrete mixture. Inactive bacteria in the destruction of concrete are activated by the penetration of water into the cracks, water destroys the capsule. Limestone, produced as a result of the life of bacteria, clogs cracks in concrete [8, 9]. American researchers (Binghamton University, New York and Rutgers University) suggested using self-healing concrete, which uses the fungus Trichoderma reesei. The formation of cracks allows water and oxygen to the fungus, so that it germinates, calcium carbonate is forms, which fills the cracks [10];

- neurotechnologies slowly but surely occupy their positions in such areas as, for example, training and education of builders, maintaining the actual state of a person in a workplace (construction site), which affects the safety of life;

- virtual, augmented and mixed reality is a logical continuation of the discoveries of the previous century (stereoscopic photos, panoramic pictures, cinematography, television, computer games). We briefly differentiate these concepts, which a layman often confuses. The main difference is in the depth of immersion. Virtual reality (VR) creates the illusion of presence (for example, moving inside the BIM model of an unbuilt construction). 
Augmented reality (AR) expands the perception by providing visual information about the real world (interactivity of physical spaces and objects: for example, mobile applications for working with a project, which allows to abandon the pile of drawings and permanent binding to computers). Mixed reality (MR) expands the perception by adding realistic objects and creatures to the world. Builders are the main customers of MR equipment, because the virtual model is the basis of sales and a means of developing the construction business.

- transformations in the energy sector, such as the transition from fossil fuels to renewable energy sources (for example, solar and wind power), were marked for construction, for example, by the need to take into account energy efficiency parameters in the construction and operation of buildings;

- the implementation of ambitious futuristic geoengineering designs, which cause a lot of controversy and global social resistance, will in any case be entrust to the builders. The rest is a matter of time;

- on the development of space technology. - K. Schwab indicates the term to within a year (2030), when a breakthrough in space exploration will take place. Private investment and government programs contribute to this scenario, and the active participation of builders in the construction of alien cities is also a matter of time. Now, on the basis of BIM technology, the development of unified information models of "Smart Cities" is underway, which, apparently, is also a predecessor, a training for creating cities outside the borders of the Earth.

The hopes and aspirations of the breakthrough technologies of Industry 4.0, described by K. Schwab, are inseparably linked with the risks that impose obligations on innovative leaders and supervisors who share responsibility for the consequences. What precautionary measures are appropriate in this case? Among such risks are an increasing level of unemployment, tension in society, the danger of a social turmoil in connection with automation and robotics, the use of artificial intelligence (AI). Analysts of the company Superjob already state that 2017 is the last year, when the total growth in the number of real jobs was recorded, and by 2022 the unemployment rate in Russia will grow to 20-25\% [11].

Psychologically, the grade is serious, but it should be taken into account that the demand for high-qualified specialists continues to grow. Consequently, the upgrading of skills and the buildup of topical competencies is a solvable task both at the individual level and at the level of an organization (a company).

Concern about the role of human competence, human judgment and intellect in connection with the delegation of a number of functions to automated systems, the modification of human tasks in connection with the automation of a number of repetitive and technical tasks is another link in the list of possible risks of transition to Industry 4.0. Mixing the physical, digital, and biological spheres involves almost unclaimed human adaptation mechanisms. Awareness of one's own uniqueness and uniqueness for a person goes to a new stage of development (or transformation) in a situation of comparison with artificial intelligence. Self-identification is compromised. The themes of revealing one's own talents, abilities, individual characteristics as resources for self-actualization and selfrealization return in a special way. K. Schwab often mentions the advantages of transferring the execution of routine, everyday work to smart machines. Namely, this means to free time for creativity. But is an individual ready for creative activity and how much will it be in demand? There is every reason to believe that it is the creative component that has long ago come to attention.

The security theme is particularly acute: the risks of cyber security (the possibility of hacking or deceiving $\mathrm{AI}$ ), the danger of using 3D-printing for mass distribution of weapons, including with the introduction of a complex material (biological tissues, cells, chemical compounds), biorisks, manipulation through technologies of changing reality, threats of an 
ethical nature in connection with the application of AI in many aspects of life, because it is necessary to take into account a wide range of problems - from scientific freedoms to human rights; the threat of confidentiality, the threat to the stability of the worldview and a sense of reality. Up to the threat to the existence of mankind (for example, long-term forecasts provided that it will not be possible to reconcile the values of AI and human). Of course, in the first place, a competent legal base carries out the guarding function, the development of which is now being provided by significant forces. But due to the pace of changes in the world, such a most modern base is often outdated by the time it is ready.

Other risks include the ambiguous consequences of the application of all technologies of the Fourth Industrial Revolution and the unpredictability of the use of biotechnologies; environmental effects of nano-pollution; the problem of investment (relevant for almost all technologies, including for the discovery, development of the introduction of new materials).

In the socio-psychological context, the greatest interest is the need to form interdisciplinary groups, international coalitions, the importance of cooperation and support of the academic community, governments and business for the collective benefit of working on (with) new materials and nanotechnologies. Collective interaction aimed at mitigating the social and political consequences of the transition to renewable energy sources. So, the introduction of BIM-technologies in construction unites around a single information model a large number of professionals who cooperate simultaneously. Representatives of not only different professions, but also different companies (for example, a large citywide project or network trading facilities) work with one task. In contrast to previous technologies, where the linear nature of work on a single building or structure was observed, when architects, engineers and designers practically did not contact each other, because of what the result was unsatisfactory.

The assiciation of people in the process of activity and communication is a general definition of a social group in which there are signs, their laws and mechanisms operate. For example, these are integral psychological characteristics such as the formation of public opinion, norms and interests, the existence of a psychological climate, one's own organizational culture, etc. The composition, structure, group processes, norms and sanctions can be classified as the main parameters of the group as a whole. Among the attributes of social groups, the participants' ability to act in concert (providing unity in the process of achieving the goal) and the action of group pressure (the person changes his (she) views and behavior in a group) are also traditionally indicated. The presence of another person changes behavior and can improve or worsen professional activity. In a group, the effectiveness of the work can be reduced, for example, because of the difficulties and losses caused by the efforts to coordinate actions. At the root of this reason for the ineffectiveness of groups is the phenomenon of social indolence: with an increase in the size of a group, each exerts less effort [12]. Inclusion in a group complicates this socialpsychological phenomenon, especially if the interaction space is not exhausted by a single social group, but constitutes a complex system of intergroup interaction [13, 14].

The introduction of advanced technologies in construction, such as BIM, in the opinion of experts (V. Talapov), provokes resistance and a number of misconceptions both at the individual level and at the level of groups (departments of an organization or companies), which requires separate clarification and allocation of resources for training. The inertia of the human psyche slows down the transition to new technologies, as customary and convenient ways of making drawings "by hand" are understandable and worked out. Work on/with a unified information model is a team work, which is undesirable or impossible with certain individual characteristics of employees. As noted by V. Talapov, over the past decades, the so-called guild "selfishness" of some groups of designers has been formed. 
The solution of the problem, as the expert notes, is command-administrative in nature (persuasion, coercion).

Intergroup interaction differs from the intra-group one, where the phenomena of intragroup favoritism and intergroup aggression, which are reflected in the process and result of common activity, are studied more often than others [13]. Unproductive rivalry and an atmosphere of hostility are the consequences of such phenomena. Here, the principles of competitiveness may not be appropriate. Many participants, being included in various social groups, uniting around a unified model of BIM are carriers of a certain culture, which fills this interaction with a certain identity and creates conditions for intergroup adaptation, which allows to optimize the interaction of groups [14].

\section{Results}

According to the tasks formulated in this paper, the following results are obtained.

1. Modern trends in construction, due to the introduction of information modeling technologies, correspond to the 12 technologies of the Fourth Industrial Revolution by K. Schwab and meet the spirit of the times with all the pros and cons. It is not possible to stop this process, but it is necessary "to keep an eye on the pulse" and to foresee possible consequences.

2. The terminological apparatus used in this paper is understandable and accessible for operation, clear, differentiated. It combines both technical and technological concepts, as well as social-psychological, since a man is the end user of the construction industry and its central link. Even in a confusion of real and virtual realities.

3. Risks of transition to Industry 4.0, including the introduction of information modeling technologies in construction, are associated with a wide range of security topics, unpredictability of the consequences of the applied (or planned) technologies. A special status is occupied by social-psychological risks: large associations of bearers of different cultures (including organizational ones for different professional groups) also differ in unpredictability providing that the process of unification and formation of a single culture will be neglected. Condoning in such a situation can be a breeding ground for such negative manifestations as social indolence, inertia of the psyche and the desire to preserve the habitual, but obsolete, inconsistent current reality the course of life. For example, it is pointless to deny the decrease in the efficiency of work with the increase in the members of working group, but it is appropriate to take this feature into account in advance.

4. Socio-psychological methods of managing inter-group interaction in social systems are a kind of compass that facilitates navigation in unclear conditions (lack of a clear legal framework, fears and anxieties, in addition to interest, when meeting new (reaction to novelty), etc.). The concept of A.V. Bulgakov of intergroup adaptation is basic. Bulgakov. Forecasts become optimistic for the constant monitoring of the features of intergroup interaction and timely application of socio-psychological measures implemented by personnel management specialists or heads of construction companies.

5. Preventive measures in the conditions under study should be aimed at the formation of a positive background of professional interaction (psychological climate, organizational culture), a spirit of cooperation conducive to the involvement of all participants of the construction organization; the development of training programs with an emphasis on the pragmatic side of the transition to new technologies. Training will help to remove the negative, as a classic manifestation of non-inclusion and lack of information. Identifying oneself with a group resisting innovations, the phenomenon of intergroup aggression arises and the forces are directed to the destruction of the organization from within. 


\section{Discussion}

It is worth mentioning that it is one of the main tasks to be included in the social context for a person, as a social creature by nature. Tracking changes and adapting to them is one of the conditions for maintaining contact with reality. On the other hand, the question of subjective assessment of what is happening remains open: phenomena that are of interest and are consistent with internal ideas, values and beliefs (resonant) are accepted and met with readiness; phenomena that come into discord with existing experience and attitudes are rejected, provoke the inclusion of psychological defense mechanisms. The Fourth Industrial Revolution globally changes the world. To comprehend, develop an adequate strategy of behavior takes time, and time is limited. The history of previous industrial revolutions shows that "outside" the globally changing world, there were individuals and large human associations. Find yourself in the new realities is the individual task for everyone, the organizational task for a company.

The mechanism of social indolence mentioned above can be prevented by such measures as the importance of the group for its participants; identification of the contribution of each participant of the working group; meaningfulness and importance assigned tasks for everyone; maintaining the belief that the personal contribution is unique and contributes to the improvement of the activity of a significant group; the difference between the work of each person (then the load and responsibility cannot be shifted to another employee); high team cohesion (with friends less idle).

In addition, it makes sense to take into account the socio-psychological differences in the optimal conditions for performing simple and complex tasks. For example, when solving simple tasks, conditions are created for common, group work in a single space, background noise is appropriate, and when solving complex problems, conditions that isolate participants from external observation and external signals are created, and in the collective work, microgroups of 2-8 people are created, background noise is excluded, because interfere with operation.

It is interesting that for several decades the negative consequences of intergroup competitions and rivalries have been known: intragroup favoritism is increasing, intergroup aggression and conflictiveness are increasing, stressorship of joint activity is increasing. At the same time, the spirit of rivalry is still one of the main incentives for managers to rely on. Team building, the stake on the solution of the common problem, task, the achievement of one goal are the more competent socio-psychological ways to improve the effectiveness of an organization.

\section{Conclusions}

Changing the ways of organizing joint activities is a necessary condition for effective work when introducing information modeling technologies in construction. With the understanding of the term "human factor" in a broad sense, as psychological and other characteristics of a person, the opportunities and limitations determined in the specific conditions of his (her) activity allow us to take this factor into account and consider it determinative in organizing work around a unified information model with a bet on strong side.

Further steps to study the socio-psychological aspects of the introduction of information modeling technologies in construction are due to the need to create and apply a set of measures for monitoring and inter-group adaptation in construction organizations. 


\section{References}

1. K. Schwab,. Technology of the Fourth Industrial Revolution (2018)

2. G. Shu, R. Anderle, Yu. Gaussemayer, Ten Hompel, M. Valster, et al., Digital Transformation Management of Companies 10 (2017)

3. Terms of EMERCOM of Russia, http://www.mchs.gov.ru/dop/terms/item/86182/

4. T.N. Magera, Economics and Entrepreneurship 10, 165-168 (2018).

5. V. Talapov BIM technology: a unified model and related misconceptions, https://stroi.mos.ru/builder_science/tiekhnologhiia-bim-iedinaia-modiel-i-sviazannyies-etim-zabluzhdieniia?from $=\mathrm{cl}$

6. Committee for Technical Regulation, Standardization and Conformity Assessment of the Russian Union of Industrialists and Entrepreneurs. http://www.rgtr.ru/press/techreg/20180725/prezident_dal_poruchenie_pravitelstvu_po_ obespecheniyu_razvitiya_bim_tekhnologij/

7. T.N. Magera Technologies of the Fourth Industrial Revolution: benchmarks for business // Economics and Entrepreneurship, 10, 165-168 (2018)

8. The Dutch microbiologist has developed self-healing concrete, https://habr.com/post/367081/

9. 6 building materials technologies that will change our future, https://hinews.ru/technology/6-texnologij-stroitelnyx-materialov-kotorye-izmenyat-nashebudushhee.html

10. Self-healing concrete is the building material of the future http://www.zetsila.ru

11. How robots replace people, http://www.tadviser.ru

12. M.V. Plotnikov, S.V. Smeltsova Modern studies of social problems, 4-8, (2011), http://cyberleninka.ru/article/n/obektivnye-faktory-vnutrigruppovogo-vzaimodeystviya

13. V.S. Ageyev Intergroup interaction: social-psychological problems (1990)

14. A.V. Bulgakov, A.V. Kidinov Psychology of intragroup relations and intergroup adaptation in organizations (2016) 